\title{
Diagnosis of pheochromocytoma with special emphasis on MEN2 syndrome
}

\author{
Karel Pacak ${ }^{1}$, Graeme Eisenhofer ${ }^{2}$, Ioannis Ilias ${ }^{3}$ \\ ${ }^{1}$ Reproductive and Adult Endocrinology Program, Section of Medical Neuroendocrinology, NICHD, National Institutes \\ of Health, Bethesda, USA, ${ }^{2}$ Institute of Clinical Chemistry and Laboratory Medicine, Department of Medicine, University \\ of Dresden, Dresden, Germany, ${ }^{3}$ Department of Endocrinology, "Elena Venizelou" Hospital, Athens, Greece
}

\begin{abstract}
Pheochromocytomas/paragangliomas (PHEOs/PGLs) are rare but treacherous catecholamineproducing tumors which, if overlooked or improperly treated, will almost invariably prove fatal. Patients with MEN2 PHEOs have a high incidence of paroxysmal attacks and a higher prevalence of hypertension and other cardiovascular problems than do patients with Von-Hippel-Lindau (VHL) PHEOs. Compared to measurements of deconjugated metanephrines, plasma concentrations of free metanephrines are relatively independent of renal function and therefore more suitable for diagnosis of PHEO/PGL. Recently, the focus of Positron Emission Tomography (PET) imaging for these tumors has been the localization of PHEO. Although a limited number of studies are available, $\left[{ }^{18} \mathrm{~F}\right]$-fluorodopamine $\left(\left[{ }^{18} \mathrm{~F}\right] \mathrm{DA}\right)$ PET has been found to be the best overall imaging modality in the localization of PHEO. For adrenal PHEOs, this method seems to be comparable to other functional modalities such as $\left[{ }^{18} \mathrm{~F}\right]$-fluorodopa $\left(\left[{ }^{18} \mathrm{~F}\right] \mathrm{DOPA}\right)$ PET or $\left[{ }^{123} I\right]$-metaiodobenzylguanidine $\left(\left[{ }^{123} I\right] M I B G\right)$ scintigraphy. For extraadrenal PHEOs, data are limited and more extensive studies are needed. In patients with metastatic PHEO, the sensitivity of $\left[{ }^{18}\right.$ F] DA PET is superior to $\left[{ }^{123} I\right]$ MIBG. The so called "flip-flop" imaging showing superiority of non-specific $\left[{ }^{18}\right.$ F] flurodeoxyglucose (FDG) PET over specific $\left[{ }^{18}\right.$ F]DA PET has been described in rapidly progressive, often metastatic SDHB-associated PHEOs. Whether these data reflect PHEO cell dedifferentiation (e.g. losing Norepinephrine Transporter - NET) or increased metabolic rate remains to be established.
\end{abstract}

Key words: Multiple endocrine neoplasia, Paraganglioma, Pheochromocytoma, Positron-emission tomography

\section{INTRODUCTION - PATHOGENESIS}

Pheochromocytomas (PHEOs) are rare chromaf-

Address for correspondence:

Ioannis Ilias, MD., Ph.D., Department of Endocrinology,

Diabetes and Metabolism, "Elena Venizelou" Hospital,

2 El. Venizelou Sq., 11521 Athens, Greece

Fax: +30 210 6411156, E-mail: iiliasmd@yahoo.com

Received 08-02-09, Revised 05-03-09, Accepted 20-03-09 fin-cell catecholamine-producing tumors, primarily located in the adrenal medulla. ${ }^{1}$ Extraadrenal chromaffin-cell tumors, known as paragangliomas (PGLs), are usually found along the paravertebral and paraaortic axes. ${ }^{2}$ Up to $24 \%$ of PHEOs/PGLs are associated with hereditary syndromes: multiple endocrine neoplasia type 2 (MEN2), von Recklinghausen's neurofibromatosis type 1 (NF-1), von Hippel- 
Lindau (VHL) syndrome and familial PGLs caused by germline mutations of the gene encoding succinate dehydrogenase (SDH) subunits B, C and D. ${ }^{3}$ Plasma or urine free metanephrines provide biochemical diagnosis of PHEOs/PGLs and tumor localization is obtained with anatomical and functional imaging modalities. ${ }^{4,5}$

Non-functioning PGLs are challenging tumors for clinicians (it should be noted that some are incompletely non-functioning and do secrete moderate amounts of vanillylmandelic acid). ${ }^{6}$ They are rare and usually asymptomatic until their size is sufficient to produce symptoms of compression on adjacent organs, especially in cases of abdominal/retroperitoneal tumors. ${ }^{7}$

Up to $36 \%$ of PHEOs are malignant. ${ }^{5}$ The annual cumulative incidence of PHEOs/PGLs is reported as approximately $3-8$ per $10^{6}$ population. ${ }^{8}$ Although MEN2-associated PHEOs are usually benign, if left untreated they can be lethal.

\section{GENETICS}

In subjects with MEN2 syndrome, activating germline mutations in the RET (REarranged during Transfection) protooncogene (usually in codons 634 or 918; 10q11.2) are found; these mutations are implicated in abnormal cellular proliferation. In patients with MEN2, PHEOs are usually adrenal, benign and bilateral in more than $50 \%$ of patients. ${ }^{9}$ Children with MEN2B-associated PHEOs have a higher risk of malignancy compared to those with MEN2A or sporadic disease. ${ }^{10}$

\section{EPIDEMIOLOGY}

PHEOs manifest in approximately $50 \%$ of patients with MEN2A or 2B, most often after the manifestation of medullary thyroid cancer (MTC) ${ }^{11}$ MTC occurs rather early in life (in the first and second decades) in patients with MEN2B and follows an aggressive, often lethal course, whereas the average age of diagnosis of MEN2-associated PHEOs is between 30-40 years. ${ }^{12}$ Almost all primary PHEOs in patients with MEN2 are localized in the adrenals; less than $5 \%$ of these PHEOs are malignant. ${ }^{11}$ At diagnosis, $30 \%$ of PHEOS in MEN2 are bilatera $\mathrm{l}^{13}$ and in $50 \%$ of patients with unilateral disease a second PHEO develops in the contralateral adrenal within ten years. ${ }^{14}$

\section{CLINICAL SYMPTOMS AND SIGNS}

The symptoms of PHEOs are variable; overall, tachycardia along with diaphoresis and cephalalgia are encountered in $40 \%-80 \%$ of patients. Although hypertension (either newly diagnosed or exacerbation of known hypertension and most often paroxysmal) is very common (in $>90 \%$ of all patients with PHEO), this symptom nevertheless remains a non-specific finding. ${ }^{15}$

In contrast to sporadic PHEOs/PGLs, those in familial syndromes, such as in MEN2 and VHL syndrome, exhibit highly distinct gene expression profiles. MEN2 tumors express phenylethanolamine $\mathrm{N}$-methyltransferase (the enzyme that converts norepinephrine to epinephrine), whereas VHL tumors do not; the latter demonstrate activation of hypoxia-angiogenic signaling pathways but also a lower expression of components implicated in catecholamine-related pathways. MEN2 tumors secrete epinephrine or epinephrine and norepinephrine in paroxysmal bursts, while PHEOs in VHL patients show a more sustained catecholamine secretory profile (Table 1). ${ }^{16}$ In VHL-related tumors, catecholamine stores are smaller and exhibit a more rapid secretion-dependent turnover compared to MEN2 tumors. The net result is that there are differences in the relative amounts of norepinephrine and epinephrine produced by these two types of tumors; the difference in potency of these catecholamines on alpha and beta adrenoreceptors has been proposed as accounting for the more symptomatic nature of PHEOs/PGLs in MEN2 (in particular for paroxysmal attacks and higher prevalence of hypertension) compared to VHL syndrome. ${ }^{13,16-18}$ Signs and symptoms such as palpitations, anxiety, tremor, dyspnea, hyperglycemia and paroxysmal hypertension are more common in patients with tumors that produce epinephrine than in those that do not. Data from our laboratory indicate that these differences are associated with much higher levels of chromogranins A and B and neuropeptide $\mathrm{Y}$ in MEN2 than VHL tumors (Table 2). ${ }^{19,20}$ 
Table 1. Comparison of PHEOs in MEN2 versus VHL

\begin{tabular}{lll}
\hline $\begin{array}{l}\text { Tumor localization } \\
\text { Biochemical phenotype }\end{array}$ & MEN2 & VHL \\
Other tumors & $\begin{array}{l}\text { Epinephrine- or epinephrine- } \\
\text { and norepinephrine-secreting } \\
\text { MTC, parathyroid hyperplasia }\end{array}$ & $\begin{array}{l}\text { Mainly adrenal } \\
\text { Norepinephrine-secreting }\end{array}$ \\
Localization modalities & $\begin{array}{l}\text { CT or MRI if tumor over 5 cm; } \\
\text { perform functional imaging to rule out } \\
\text { metastatic disease }\end{array}$ & $\begin{array}{l}\text { Hemangioblastomas, renal cell carcinoma, pancreatic } \\
\text { tumors (possibly neuroendocrine tumors) } \\
\text { Always use functional imaging since NE phenotype } \\
\text { suggests that tumor can be located in extraadrenal } \\
\text { locations* }\end{array}$ \\
\hline
\end{tabular}

*It is very common that in older age adrenal benign adenomas are present

PHEOs: pheochromocytomas, VHL: von Hippel-Lindau, MEN2: multiple endocrine neoplasia type 2, MTC: medullary thyroid cancer, CT: computed tomography, MRI: magnetic resonance imaging, NE: norepinephrine

Table 2. Symptoms of PHEOs/PGLs according to their neurosecretory products and in particular of Neuropeptide Y (NPY), which is a vasoactive peptide that may contribute to their clinical presentation. Patients with MEN2 or sporadic PHEOs show high levels of NPY compared to VHL-associated tumors (modified/ adapted from ${ }^{3,19}$ )

\begin{tabular}{lcccc}
\hline & \multicolumn{2}{c}{$\begin{array}{c}\text { High NPY } \\
\text { expression }\end{array}$} & & $\begin{array}{c}\text { Low NPY } \\
\text { expression }\end{array}$ \\
\cline { 2 - 3 } \cline { 5 - 5 } & MEN2 & $\begin{array}{c}\text { Sporadic } \\
\text { disease }\end{array}$ & & VHL \\
\hline Hypertension (\%) & 42 & 90 & & 19 \\
Headache (\%) & 32 & 92 & & 26 \\
Diaphoresis (\%) & 32 & 70 & & 23 \\
Palpitations (\%) & 37 & 73 & & 19 \\
Anxiety (\%) & 21 & 60 & & 16 \\
Total symptoms (\%) & 53 & 90 & & 32 \\
\hline
\end{tabular}

\section{BIOCHEMICAL DIAGNOSIS}

PHEOs may secrete catecholamines episodically but they metabolize catecholamines to metanephrines continuously. Plasma concentrations of free metanephrines are relatively independent of renal function and therefore more suitable for diagnosis of PHEO/ PGL. The measurement of plasma metanephrines is less cumbersome than determinations in urine and implementation of this test is expanding. Plasma free metanephrines and 24-hour urinary fractionated free metanephrines are accurate, though not infallible, methods for establishing the diagnosis of PHEO/PGL: their sensitivities are 96\%-100\% and $92 \%-99 \%$, whereas their specificities are $87 \%$ $92 \%$ and $64 \%-72 \%$, respectively. ${ }^{21-24}$ Thus, plasma and urine metanephrines should be considered to be complementary rather than mutually exclusive methods. Normalization of metanephrine levels for populations with normal blood pressure and also for gender and age should be sought, ${ }^{25}$ as well as avoidance of interference from medications. ${ }^{26} \mathrm{We}$ have also found that measurements of plasma free metanephrines not only provide information about the likely presence or absence of a PHEO/PGL but, when a tumor is present, can also help to predict tumor size and location, ${ }^{26}$ since biochemical measurements of blood or urine catecholamines are poorly correlated with tumor size, whereas blood or urine metanephrines show strong correlation with tumor size and can be useful in judging the extent and progression of the disease. ${ }^{4}$ The PHEOs in MEN2 patients entail a distinct biochemical phenotype in that they consistently produce epinephrine or epinephrine and norepinephrine.

\section{PHEO LOCALIZATION}

Anatomical imaging with computed tomography (CT) and/or magnetic resonance imaging (MRI) is used in patients with biochemically-proven PHEOs/ PGLs (Table 1). While for most patients imaging is limited to the adrenals/abdomen, imaging of the thorax, neck and head are ordered when malignant/ metastatic disease is suspected. PHEOs enhance avidly after contrast medium administration on CT; their contrast washout phase is also prolonged. ${ }^{27} \mathrm{CT}$ has $93 \%-100 \%$ sensitivity in detecting intraadrenal tumors $>0.5 \mathrm{~cm} .{ }^{28}$ Sensitivity is slightly lower $(90 \%)$ 
for localizing extraadrenal PHEOs $>1 \mathrm{~cm} .{ }^{28} \mathrm{MRI}$ is as good as or slightly better than CT for localizing PHEOs; moreover, MRI can detail the relationship of tumors with blood vessels, a feature appreciated when surgery is considered. Although on T2-weighted MRI sequences some adrenal PHEOs show homogeneously high signal intensity, in a recent study most tumors had heterogeneous multiple high intensity areas. ${ }^{29}$

While experience is limited regarding non-functioning PGLs, anatomical imaging cannot reliably differentiate functioning from non-functioning lesions, as is also the case with adrenal tumors, ${ }^{27}$ biochemical evaluation-on more than one occasion-is needed to further advance the diagnostic work-up. ${ }^{30}$

There are some caveats in the anatomical imaging for PHEOs/PGLs. False-positive CT/MRI studies can ensue ${ }^{31}$ and the specificity of CT/MRI may vary from $50 \%-90 \% .{ }^{9}$ In patients with previous surgery, anatomical imaging may not be informative to the clinician, particularly for recurrent, extraadrenal or malignant/metastatic disease. ${ }^{28}$ For such patients, functional imaging (implementing nuclear medicine modalities) follows anatomical imaging.

Chromaffin tumors express the human norepinephrine transporter (hNET) and enable the use of specific radiolabeled ligands of molecules that enter the catecholamines' synthesis pathway. Nuclear medicine also makes use of non-specific modalities (since PHEOs/PGLs exhibit high glucose metabolism or express somatostatin receptors). ${ }^{32}$ The first choice among nuclear medicine methods is with specific ligands and modalities and, if negative, with nonspecific modalities (particularly if recurrent, metastatic or malignant disease is suspected).

Metaiodobenzylguanidine (MIBG) is a catecholamine precursor that is taken into PHEOs via hNET. It is more commonly labeled with iodine-123 $\left[{ }^{123} \mathrm{I}\right]$ than iodine-131 [ $\left.{ }^{131} \mathrm{I}\right]$. Sensitivity of $\left[{ }^{123} \mathrm{I}\right] \mathrm{MIBG}$ for PHEOs/PGLs is $63 \%-100 \%$ versus $77 \%-90 \%$ of $\left[{ }^{131} I\right] M I B G$ (sensitivity is lower for extraadrenal and/or metastatic disease); ${ }^{28,33,34}$ their specificity is 95\%-100\%..$^{35,36}$ MIBG's suboptimal sensitivity is attributed to its low affinity for hNET (the latter's loss possibly resulting from tumor cell dedifferentiation), lack of storage granules, altered vesicle transporter or interference by medications. ${ }^{37}$
Recently, the focus of Positron Emission Tomography (PET) imaging has been the localization of PHEO/PGLs. Although a limited number of studies are available, $\left[{ }^{18} \mathrm{~F}\right]$-fluorodopamine $\left(\left[{ }^{18} \mathrm{~F}\right] \mathrm{DA}\right)$ PET has been found to be the best overall imaging modality in the localization of PHEOs. ${ }^{34}$ This is more relevant in cases of familial PHEOs, such as in VHL-associated tumors, where functional imaging with $\left[{ }^{18} \mathrm{~F}\right] \mathrm{DA}$ PET was demonstrated to be superior to $\left[{ }^{123 / 131}\right.$ I] MIBG. ${ }^{37}$ For adrenal PHEOs, this method seems to be equal to other functional modalities such as $\left[{ }^{18} \mathrm{~F}\right]$-fluorodopa $\left(\left[{ }^{18} \mathrm{~F}\right] \mathrm{DOPA}\right) \mathrm{PET}$ or $\left[{ }^{123} \mathrm{I}\right] \mathrm{MIBG}$ scintigraphy. For extraadrenal PHEOs, data are limited and more extensive studies are needed. In patients with metastatic PHEO, the sensitivity of $\left[{ }^{18} \mathrm{~F}\right] \mathrm{DA}$ PET is superior to that of $\left[{ }^{123} \mathrm{I}\right] \mathrm{MIBG}(78 \%$ vs 59\%). ${ }^{34}$ Comparison studies between Octreoscan and $\left[{ }^{18} \mathrm{~F}\right] \mathrm{DOPA}$ PET are in progress. The so-called "flip-flop" imaging effect (showing superiority of nonspecific $\left[{ }^{18} \mathrm{~F}\right]$-fluorodeoxyglucose PET over specific $\left[{ }^{18} \mathrm{~F}\right] \mathrm{DA} \mathrm{PET}$ ) has been described in rapidly progressive, often metastatic Succinate Dehydrogenase complex subunit B (SDHB)-associated tumors. Whether these data reflect PHEO cell dedifferentiation (e.g. losing hNET) or increased metabolic rate remains to be established. Functional imaging with $\left[{ }^{18} \mathrm{~F}\right] \mathrm{DA}$ PET is useful in the clinical follow-up of patients with familial PHEO: it has proven itself as a useful modality in patients with recurrent disease and experience has shown that it might not be unwise to order functional imaging even in the case of equivocal or slightly positive biochemical findings. ${ }^{37}$

Somatostatin receptors (ST-R) are expressed to some extent by PHEOs/PGLs (mostly types 2, 3 and 5). ${ }^{34}$ ST-R scintigraphy (SRS) is useful for localizing malignant/metastatic PHEOs/PGLs with sensitivity approaching $69 \%-90 \% .34,38$

\section{Acknowledgement}

This work was supported in part by the Intramural Research Program of the National Institute of Child Health and Development. The authors have no conflict of interest to disclose.

\section{REFERENCES}

1. Lack EE 1997 Developmental, physiologic and anatomic aspects of adrenal cortex and medulla. In: Tumors of the 
adrenal gland and extra-adrenal paraganglia. Washington, DC: Armed Forces Institute of pathology: 1-31.

2. Young WF, 2006 Paragangliomas: clinical overview. Ann N Y Acad Sci 1073: 21-29.

3. Pacak K, Lenders JWM, Eisenhofer G 2007 Current trend in genetics of pheochromocytoma. In: Pheochromocytoma: diagnosis, localization and treatment. Malden, MA: Blackwell, pp, 30-40.

4. Pacak K, Lenders JWM, Eisenhofer G 2007 Current trends in biochemical diagnosis of pheochromocytoma. In: Pheochromocytoma, diagnosis, localization and treatment. Malden, MA: Blackwell, pp, 72-92.

5. Pacak K, Lenders JWM, Eisenhofer G 2007 Clinical presentation of pheochromocytoma. In: Pheochromocytoma: diagnosis, localization and treatment. Malden, MA: Blackwell, pp, 8-29.

6. Kimura N, Miura Y, Nagatsu I, Nagura H, 1992 Catecholamine synthesizing enzymes in 70 cases of functioning and non-functioning phaeochromocytoma and extraadrenal paraganlioma. Virchows Archiv A Pathol Anat 421: 25-32.

7. Law NW, Alfano L, 1987 Non-functioning retroperitoneal paraganlioma. J Royal Soc Med 80: 246-247.

8. Pacak K, Lenders JWM, Eisenhofer G 2007 Introduction. In: Pheochromocytoma diagnosis, localization and treatment. Malden, MA: Blackwell, pp, 1-2.

9. Mittendorf EA, Evans DB, Lee JE, Perrier ND, 2007 Pheochromocytoma: advances in genetics, diagnosis, localization, and treatment. Hematol Oncol Clin North Am 21: 509-525.

10. Ross JH, 2000 Pheochromocytoma. Special considerations in children. Urol Clin North Am 27: 393-402.

11. Gimm O, Koch CA, Januszewicz A, Opocher G, Neumann HP, 2004 The genetic basis of pheochromocytoma. Front Horm Res 31: 45-60.

12. Bryant J, Farmer J, Kessler LJ, Townsend RR, Nathanson KL, 2003 Pheochromocytoma: the expanding genetic differential diagnosis. J Natl Cancer Inst 95: 1196-1204.

13. Kaltsas GA, Papadogias D, Grossman AB, 2004 The clinical presentation (symptoms and signs) of sporadic and familial chromaffin cell tumours (phaeochromocytomas and paragangliomas). Front Horm Res 31: 61-75.

14. Frank-Raue K, Kratt T, Hoppner W, Buhr H, Ziegler R, Raue F, 1996 Diagnosis and management of pheochromocytomas in patients with multiple endocrine neoplasia type 2-relevance of specific mutations in the RET proto-oncogene. Eur J Endocrinol 135: 222-225.

15. Kaplan NM 2006 Pheochromocytoma with a Preface About Incidental Adrenal Masses. In: Kaplan's clinical hypertension. Philadelphia, PA: Lippincott, Williams \& Wilkins, pp, 389-433.

16. Pacak K, Lenders JWM, Eisenhofer G 2007 Catecholamines and adrenergic receptors. In: Pheochromocytoma: diagnosis, localization and treatment. Malden, MA: Blackwell, pp, 41-71.

17. Eisenhofer G, Walther MM, Huynh TT, et al, 2001
Pheochromocytomas in von Hippel-Lindau syndrome and multiple endocrine neoplasia type 2 display distinct biochemical and clinical phenotypes. J Clin Endocrinol Metab 86:1999-2008.

18. Young WF 2008 Pheochromocytoma and paraganglioma. In: Kronenberg HM, Melmed S, Polonsky KS, Larsen PR, eds. Williams Textbook of Endocrinology. Philadelphia, PA: Saunders, pp, 507-521.

19. Cleary S, Phillips JK, Huynh TT, et al, 2007 Neuropeptide Y expression in phaeochromocytomas: relative absence in tumours from patients with von Hippel-Lindau syndrome. J Endocrinol 193: 225-233.

20. Brouwers FM, Gläsker S, Nave AF, et al, 2007 Proteomic profiling of von Hippel-Lindau syndrome and multiple endocrine neoplasia type 2 pheochromocytomas reveals different expression of chromogranin B. Endocr Relat Cancer 14: 463-467.

21. Raber W, Raffesberg W, Bischof M, et al, 2000 Diagnostic efficacy of unconjugated plasma metanephrines for the detection of pheochromocytoma. Arch Intern Med 160: 2957-2963.

22. Lenders JW, Pacak K, Walther MM, et al, 2002 Biochemical diagnosis of pheochromocytoma: which test is best? JAMA 287: 1427-1434.

23. Sawka AM, Jaeschke R, Singh RJ, Young WF, 2003 A comparison of biochemical tests for pheochromocytoma: measurement of fractionated plasma metanephrines compared with the combination of 24-hour urinary metanephrines and catecholamines. J Clin Endocrinol Metab 88: 553-558.

24. Václavík J, Stejskal D, Lacnák B, et al, 2007 Free plasma metanephrines as a screening test for pheochromocytoma in low-risk patients. J Hypertens 25: 1427-1431.

25. Grossman A, Pacak K, Sawka A, et al, 2006 Biochemical diagnosis and localization of pheochromocytoma: can we reach a consensus? Ann N Y Acad Sci 1073: 332-347.

26. Eisenhofer G, Lenders JW, Pacak K, 2004 Biochemical diagnosis of pheochromocytoma. Front Horm Res 31:76-106.

27. Ilias I, Sadhev A, Reznek RH, Grossman AB, Pacak K, 2007 The optimal imaging of adrenal tumors: a comparison of different methods. Endocr Relat Cancer 14: 587-599.

28. Ilias I, Pacak K, 2004 Current approaches and recommended algorithm for the diagnostic localization of pheochromocytoma. J Clin Endocrinol Metab 89: 479. 491.

29. Jacques AE, Sahdev A, Sandrasagara M, et al, 2008 Adrenal phaechromocytoma: correlation of MRI appearances with histology and function. Eur Radiol 18: 2885-2892.

30. Zianni D, Tzanela M, Klimopoulos S, Thalassinos NC, 2004 Symptomatic pheochromocytoma with normal urinary catecholamine metabolites. Hormones (Athens) 3: 132-137.

31. Go AS 1998 Refining Probability: An Introduction to 
the Use of Diagnostic Tests. In: Friedland DJ, ed. Evidence-Based Medicine. New York, NY: McGraw-Hill, pp,12-33.

32. Shulkin BL, Ilias I, Sisson JC, Pacak K, 2006 Current trends in functional imaging of pheochromocytomas and paragangliomas. Ann N Y Acad Sci 1073: 374-382.

33. Van Der Horst-Schrivers AN, Jager PL, Boezen HM, Schouten JP, Kema IP, Links TP, 2006 Iodine-123 metaiodobenzylguanidine scintigraphy in localising phaeochromocytomas--experience and meta-analysis. Anticancer Res 26: 1599-1604.

34. Ilias I, Chen CC, Carrasquillo JA, et al, 2008 Comparison of 6-[18F]-fluorodopamine positron emission tomography to [123I]-metaiodobenzylguanidine and [111In]-pentetreotide scintigraphy in the localization of non-metastatic and metastatic pheochromocytoma. J Nucl Med 49: 1613-1619.
35. Ilias I, Yu J, Carrasquillo JA, et al, 2003 Superiority of 6 -[18F]-fluorodopamine positron emission tomography versus [131I]-metaiodobenzylguanidine scintigraphy in the localization of metastatic pheochromocytoma. J Clin Endocrinol Metab 88: 4083-4087.

36. Cleary S, Phillips JK, 2006 The norepinephrine transporter and pheochromocytoma. Ann N Y Acad Sci 1073: 263-269.

37. Kaji P, Carrasquillo JA, Linehan WM, et al, 2007 The role of $6-[18 \mathrm{~F}]$ fluorodopamine positron emission tomography in the localization of adrenal pheochromocytoma associated with von Hippel-Lindau syndrome. Eur J Endocrinol 156: 483-487.

38. Ilias I, Pacak K, 2008 A clinical overview of pheochromocytomas, paragangliomas and carcinoid tumors Nucl Med Biol 35: Suppl 1: 27-34. 